Table 1

Mean Latencies (Msec) of Responding in Each Session by Groups $A$ and $B$

\begin{tabular}{cccccccccccc}
\hline & Condition & 1 & 2 & 3 & 4 & & Condition & 5 & 6 & 7 & 8 \\
\hline Group A & $\mathrm{m}-6$ & 899 & 744 & 740 & 687 & $\mathrm{~m}-14$ & 740 & 715 & 719 & 686 \\
Group B & $\mathrm{m}-14$ & 806 & 771 & 726 & 694 & $\mathrm{~m}-6$ & 637 & 632 & 613 & 606 \\
\hline
\end{tabular}

condition, and block number within session, formed the "within-S" or repeated measurements variables. Block number was treated as a fixed-effects variable, since a signaled midsession pause produced a significant blocks-within-session effect $\left[F=5.47, F_{.01}(15,150)=2.34\right]$

RTs in the "m-6" condition were significantly faster than in the " $\mathrm{m} \cdot 14$ " condition $[\mathrm{F}=17.75$, $\left.F_{.01}(1.10)=10.04\right]$. Ss who were exposed to " $\mathrm{m}-6$ " tapes in the first four sessions (Group A) show an average increase of $53 \mathrm{msec}$ in RT in Session 5 when switched to the " $\mathrm{m}-14$ " tapes. Conversely, for Group B Ss, the effect of switching to "m-6" tapes at Session 5 was an average 57 -msec decrease in RT.

An analysis of the sequence of block medians within Session 5 was undertaken in order to determine if the shifts to slower or faster responding could be observed within this transition session. However, the trend within this session was not different from that seen in other sessions.

The practice effects variable (session-within-condition) was significant at the .01 level $[\mathrm{F}=10.40$, $\left.F_{.01}(2,20)=5.72\right]$. This effect was the same for both groups under both conditions (Group by Session interaction, $\mathrm{F}=0.22$ : $\mathrm{m}(\mathrm{S})$ Condition by Session interaction, $F=0.56$; Group by Session by Condition interaction, $F=1.25$ ). Therefore. the effect of the difference in stimulus set size on average RT can be estimated by comparing the grand means of the " $\mathrm{m}-6$ " and " $\mathrm{m}-14$ " latencies, respectively. This estimated effect is $52 \mathrm{msec}$.

Error rate was $5.5 \%$ of all responses on which block medians were based. There was no significant difference between number of errors in " $m-6$ " and " $m-14$ " conditions (118 to 129 , respectively, out of a total of $4,6083 \mathrm{rd}$-, $7 \mathrm{th}$-, and 11 th-trial responses). A rank-order correlation between error rate of individual $S$ s and amount of upward (Group A) or downward (Group B) shift in RT between Sessions 4 and 5 was not significant (rho $=.01)$.

\section{DISCUSSION}

The interesting implication of these results appears to be the following: Stimuli encountered on previous trials but not present on a current trial influence the process of comparing display items with the sample. We favor a feature-testing model to account for these results. The idea that stimulus recognition in visual search and matching is carried out in terms literature (Gibson, Gibson, Pick, \& Osser, 1962; Neisser, 1967).

A "feature" is an attribute of a stimulus, such as "acute angle at the top," which can be considered to be in one of two states Comparison involves the testing of the value or state of each feature from a display item against the value of the corresponding feature accessed from the sample in short-term memory. If all features have the same value, the decision of the feature-testing mechanism is "match," and the approach response is selected for immediate execution. If one or more of the corresponding feature states are different, $S$ proceeds to the next item in the display. Beyond the idea that $S$ tends to test more features when faced with a larger stimulus set, this experiment provides no evidence as to the specific mechanics of a model suitable for MTS.

One attractive model is based on the hypothesis that a well-practiced $\mathrm{S}$ tends to use the same set of features from trial to trial, but requires more features the larger of features has been discussed in the (e.g., "present" or "not present").

\section{TAY WILSON, Department of Transport, Toronto, Ontario, Canada}

Sevent1'-seren second-1'ear university, students were required to choose between pairs of one-outcome gambles. The adequacy of four utility models in predicting choice behavior was tested using the $m(S)$ condition. However, under this model, we might expect the transition session of Group A to show an increase in the rate of errors early in the session followed by a gradual adjustment, reflected in increasing RT, to the new stimuli. Group B's adjustment to fewer stimuli in Session 5 might be expected to appear gradually throughout the session. Instead, adjustment appeared to be virtually immediate for both groups of Ss. This remains a problem for further study.

These results can be related to the broader concept of expectancy or psychological set. They support the notion that a human searching an environment for an object is influenced by what he might expect to see as well as by what is there.

\section{REFERENCES}

GIBSON, E. J., GIBSON, J. J., PICK, A. D., \& OSSER, H. A developmental study of the discrimination of letter-like forms. Journal of Comparative \& Physiological Psychology, 1962, 55, 897-906.

HICK. W. E. On the rate of gain of information. Quarterly Journal of Experimental Psychology, 1952, 4, 11-26.

MYERS, J. L. Fundamentals of experimental design. Boston: Allyn \& Bacon, 1966.

NEISSER, U.' Cognitive psychology. New York: Appleton-Century-Crofts, 1967.

SMITH, F. E. Choice reaction time: An analysis of the major theoretical positions. Psychological Bulletin, 1968,69, 77-110.

STONE, G. C. Response latency in human matching-to-sample. Perception \& Psychophysics, 1970, 7, 197-205.

WELFORD, A. T. The measurement of sensory-motor performance: Survey and reappraisal of twelve years' progress. Ergonomics, 1960, 3, 189-229.

\title{
The effect of defensiveness and anxiety on the ability of four gambling models to predict risk-taking behavior
}

the Coombs \& Bezembinder (1964) technique for several personality' subgroups. It was found that, in general. models taking into account the subjective probability of the $S$ and the subjective utility of the prize for the $S$ were more adequate as predictors of behavior than were those using objective measures of 
these variables. Furthermore, it was found that models using subjective probability were differentially effective in predicting risk-taking behavior for various personality subgroups. In particular, fewer males who were either high anxious/high defensive or low anxious/low defensive obeyed subjective probability theories than did males who were either low anxious/high defensive or high anxious/low defensive.

This study was conducted in order to examine the effects of the personality variables of anxiety and defensiveness on the predictive efficacy of four expectation models in determining risk-taking behavior in a gambling task. Edwards (1954) described four models, EV, EU, SEV, and SEU, that have been used as a basis for the experimental study of gambling decisions. Each model predicts that the $S$ will maximize the long-term gain represented by the product of the probability of winning and the value of the prize. However, they differ in their use of objective or subjective probability of winning and/or objective value or subjective utility of the prize. The four functions that are predicted to be maximized by the inidividual theories are listed below:

$$
\begin{aligned}
E V & =p v \\
E U & =p u \\
S E V & =s v \\
S E U & =s u
\end{aligned}
$$

Where $p$ is the actual probability of winning, $s$ is the subjective probability of winning, $v$ is the actual value of the prize, and $u$ is the subjective value of the prize. Thus, for instance, SEU theory predicts that an individual will behave in a gamling situation in a manner such as to maximize the product of his subjective probability of winning and his subjective value of the prize. Pruitt (1962) has reviewed the applicability and the methodological difficulties in testing the four models of gambling behavior.

One of the major difficulties in testing the models, that of developing an independent measure of both the subjective probability of winning and the utility of the prize, has been circumvented by the Coombs \& Bezembinder (1964) technique of comparing consistencies in repeated choice behavior under assumptions particular to each of the four models. Using this technique, they found a decreasing frequency of rejection of the models as being better than no model assumptions at all as predictors of individuals' gambling behavior in the following order: EV theory, EU and SEV theory, and finally SEU theory.

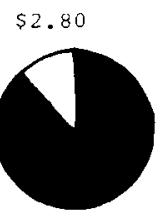

Fig. 1. A typical choice pair of gambles presented to Ss.

Kogan \& Wallach (1964) have found that high-anxious/high-defensive and low-anxious/low-defensive Ss tended to exhibit a more stable or consistent pattern of risk-taking behavior than low-anxious/high-defensive or high-anxious/low-defensive individuals. This finding suggests that methods of testing gambling models that depend upon consistency in individual responses should be sensitive to differences among $S s$ in these personality variables.

It was decided first to attempt to replicate the Coombs \& Bezembinder (1964) finding and, second, to examine whether or not the ability of the various gambling models to predict a $S$ 's behavior depends upon the personality variables of anxiety and defensiveness.

\section{PROCEDURE}

Seventy-seven second-year psychology students were presented with a series of three sets of 32 one-outcome gambles following the Coombs and Bezembinder technique. On each gamble, the $S$ was asked to determine which of two choices he would make if he were to play the game. One alternative consisted of a low probability of winning and large prize, and the other alternative consisted of a high probability of winning, but a small prize. The probability of winning was indicated by the proportion of a circle that was shaded black. The value of the prize was typed below the circle. Probabilities of winning ranged from 0.1 to 0.9 , while prize values varied from $\$ 0.80$ to $\$ 3.20$. An example of a typical choice pair of gambles appears in Fig. 1. An attempt to motivate Ss to respond as if they were really playing the game was made by informing the $\mathrm{Ss}$ that $10 \%$ of them would be given the opportunity to play the game for real with the actual choices that they had made.

Ss were then given the Alpert and Haber Test Anxiety Scale (Alpert \& Haber, 1960) and the Crowne and Marlowe Defensiveness Scale (Crowne \& Marlow, 1960).

\section{RESULTS}

The finding of Coombs and Bezembinder that the order of the gambling models in terms of their efficacy in predicting choice behavior was essentially replicated. It was found that EV theory was rejected as an adequate explanation of gambling behavior for 57 Ss, EU for $31 \mathrm{Ss}$, SEV for $26 \mathrm{Ss}$, and SEU theory for 14 Ss.

Defining high or low anxiousness or defensiveness by taking the upper or lower quartiles of the personality test scores, it was found that significantly fewer high-defensive than low-defensive Ss appeared to obey SEV theory (chi-square test, $\mathrm{p}<.01$ ). Furthermore, fewer males who were either high anxious/high defensive or low anxious/low defensive obeyed SEU or SEV theory than did males who were either low anxious/high defensive or high anxious/low defensive (chi-square test, $p<.05$ ). No other comparisons proved to be significant. DISCUSSION

For both the Coombs and Bezembinder study and the present study, not only was the order of adequacy of the gambling modes the same, but the proportion of Ss rejected for the several theories was similar. Thus, in both studies, a relatively large proportion of Ss was found to obey SEU theory, a small proportion obeyed EV theory, and intermediate proportions of Ss obeyed SEV and EU theory. These parallel findings for ostensibly diverse Ss (many of Coombs and Bezembinder's Ss were adults of low socio-economic status) suggest a pattern that may be generalizable to the population as a whole.

It appears from this data that the personality variables studied only result in behavioral differences when subjective probability is taken into account (SEU and SEV theories). Since fewer high-defensive/high-anxious and low-defensive/low-anxious Ss' gambling behavior was predictable by means of the assumptions in SEU and SEV theory, it appears that another variable, other than subjective probability and subjective utility of the prize, is needed in order to make reasonable behavior predictions of Ss who are in this personality category. REFERENCES

ALPERT R., \& HABER, R. N. Anxiety in academic achievement situations. Journal of Abnormal \& Social Psychology, 1960, 61, 207-215.

COOMBS, C. H., \& BEZEMBINDER, T. G. G. Testing expectation theories without measuring utility of subjective probability. Michigan Mathematical Psychology Program, $1965,2$.

CROWNE, D. P., \& MARLOWE, D. A new scale of social desirability, independent of psychopathology. Journal of Consulting Psychology, 1960, 24, 349-354.

EDWARDS, W. Theory of decision making. Psychological Bulletin, 1954, 51, 380-417.

KOGAN, N., \& WALLACH, M. A. Risk taking: $A$ study in cognition and personality. New York: Holt, Rinehart \& Winston, 1964.

PRUITT, D. G. Pattern and level of risk in gambling decisions. Psychological Review, $1962,69,187-201$. 